\title{
A further lesson from existing kidney markets
}

Erik Malmqvist

\section{Linköping University Post Print}

\section{Tweet}

N.B.: When citing this work, cite the original article.

This is an electronic version of an article published in:

Erik Malmqvist, A further lesson from existing kidney markets, 2014, American Journal of Bioethics, (14), 10, 27-29.

American Journal of Bioethics is available online at informaworld ${ }^{\mathrm{TM}}$ :

http://dx.doi.org/10.1080/15265161.2014.947799

Copyright: Taylor \& Francis (Routledge): STM, Behavioural Science and Public Health Titles http://www.routledge.com/

Postprint available at: Linköping University Electronic Press

http://urn.kb.se/resolve?urn=urn:nbn:se:liu:diva-110838 


\section{A further lesson from existing kidney markets}

Erik Malmqvist, Linköping University, Department of Thematic Studies, SE-58183

Linköping, Sweden. E-mail: erik.malmqvist@liu.se.

The target article challenges the increasingly popular portrayal of living kidney sale as potentially a mutually beneficial arrangement, capable not only of saving or improving the lives of patients in need of transplants but also of significantly benefiting poor vendors.

Carefully reviewing the literature on harms to vendors in illegal kidney markets and in Iran's legal market, Koplin (2014) argues that many of these harms would persist in the sort of legal regulated system that kidney sale advocates envision. This is an important argument. The kidney sales debate has been skewed in favor of permitting sales by a simplified view of the potential harms involved and excessive optimism about the capacity of regulation to prevent these harms (Malmqvist 2013). The article counterbalances these tendencies and thus considerably weakens the case for allowing sales. Nonetheless, some market proponents might remain unconvinced. I shall suggest that in addition to the lessons that Koplin draws from existing kidney markets, there is yet another one, which casts further doubt on the advisability of allowing kidney sales.

Suppose that Koplin's assessment of the harmfulness of living kidney sale in a legal regulated system is roughly correct. This might not be enough to make friends of kidney markets change their views. They could continue defending a market approach in at least three ways. First, they might propose confining the market to the societies where the harms that Koplin identifies are least likely to occur. Vendors would be much less susceptible to harms associated with low socioeconomic status, poor follow-up attendance, and lost employment in countries with robust welfare systems and universal health care than in 
countries where organ trade currently abounds (Omar et al. 2010). Second, as Koplin notes, kidney sale advocates might concede that vendors would risk serious harm even in a regulated market, but argue that these harms are outweighed by the potential benefits to kidney recipients. Third, as Koplin also notes, they might appeal to the autonomy of potential vendors. People should be allowed to decide for themselves whether the risks of selling a kidney_-significant as they may be — are worth taking, the argument goes, rather than having that decision paternalistically made on their behalf.

Each of these responses has some prima facie plausibility. However, another look at the literature on existing organ markets makes them lose much of their appeal. Not only does this literature provide reasons to believe that vendors would risk significant harm even in a carefully regulated system of sales, as Koplin points out. It also raises serious concerns about the vendors' consent, some of which seem likely to remain in such a system.

The quality of consent in existing organ markets is often questionable, to say the least. Vendors frequently report poor understanding of the consequences of the sale as well as coercion and deception at the hands of brokers (Awaya et al. 2009, Goyal et al. 2002, Zaarghoshi 2001). These deficiencies could presumably be reduced in a carefully regulated system where middlemen are removed and vendors receive appropriate information and counseling. Much depends on the effectiveness of regulation, of course. It is one thing to introduce protective measures and quite another to ensure that relevant parties comply with them - a crucial point that supporters of regulated organ markets tend to overlook. However, ensuring understanding may in principle be no more difficult than in unpaid donation schemes. And there would seem to be little room for brokering in the sort of single-buyer, fixed price system without interaction between vendors and recipients that organ sale proponents typically envision (Omar et al. 2010). 
However, other deficiencies in consent are likely to prove more intractable. Some kidney vendors in India (Goyal et al. 2002), Pakistan (Naqvi et al. 2007), and Iran (Zargooshi 2001) report having been coerced or pressured to sell by family members, debt collectors, or employers. The potential for similar pressure on vendors in the sort of regulated system that kidney sale advocates propose must not be underestimated (Malmqvist 2013, 2014). Such a system would, after all, put a price on kidneys. A person's kidney would be a potential economic asset not only for her, but also for others. Anyone with an interest in or claim on her money would then have an incentive to try to make her cede it. It seems naïve to deny that some may be prepared to resort to coercion or other forms of illegitimate influence to achieve that goal.

It might be objected that there is no difference between commercial and altruistic systems in this regard, because unpaid living donors may also be coerced. It is true that unpaid donors are often under heavy emotional pressure from family members to donate. However, the potential for coercive pressure would considerably increase with the introduction of payment. Vendors are no less susceptible than donors to family pressure, but arguably more so: financial need seems equally likely as the need for an organ to make relatives contemplate coercion, and it is undeniably much more common. And unlike donors, vendors are susceptible to pressure from anyone outside of their family interested in their money.

In this connection it is important to note that, like in existing kidney markets (Awaya et al. 2009, Naqvi et al. 2007, Zargooshi 2001), vendors would primarily be recruited among the very poor. A financial incentive is clearly more attractive the greater one's economic need. We should certainly not exaggerate the influence of poverty on decisionmaking. A poor person who sells a kidney because she lacks other ways to improve her situation could be making a genuine, reasonable choice in harsh circumstances. A limited 
range of options does not entail incapacity to choose among the few options one has, as kidney sale proponents emphasize (Wilkinson 2003). But the significance of poverty should not be underestimated either. Poverty makes one especially vulnerable to the sort of coercive influence described above. One is likely both to face heavy expectations to provide money for other people (moneylenders, needy dependents, etc.) and to have little opportunity to obtain the needed funds. One is therefore susceptible to being pressured by others to raise money in ways one would not voluntarily pursue - for instance by selling a kidney.

Some might propose regulation to handle this problem. One approach might be to delay payment in order to discourage coercion. Potential coercers may not be prepared to wait for the desired money for months or years. However, those most inclined to sell- the very poor - are unlikely to want to wait either, and so much fewer vendors would come forward. Another approach might be to screen out coerced vendors through careful assessments of decision-making capacity, motivation, and personal circumstances. However, apart from being costly, such assessments would likely be experienced as intrusive and thus discourage many other vendors as well. Again, much fewer organs would be obtained. Both forms of regulation would considerably limit the efficiency of the organ market - its main rationale - and decision-makers may therefore be reluctant to introduce them.

There is reason to believe, then, that concerns about vendors' consent would remain even in a carefully regulated kidney market. These concerns complicate the three possible defenses of such markets noted at the beginning of this commentary. Coercive pressure on vendors cannot be ruled out even in countries with welfare systems and universal health care, in part because even these countries have poor populations vulnerable to such pressure, which is where vendors would primarily be recruited. And harms to vendors are much harder to justify by invoking their autonomy if some vendors incur these harms 
involuntarily. Nor are they easily justified by appealing to benefits to kidney recipients; we rightly hesitate to benefit some people by significantly harming others against their will.

The considerations about consent that I have discussed here thus complement the harm-based ones insightfully discussed by Koplin. Taken together they present a powerful challenge to the pro-market view - though perhaps not a decisive one, as benefits to kidney recipients remain a potentially weighty countervailing consideration. More specifically, I believe they together support the sort of rationale for banning sales I have detailed elsewhere. Under this rationale, all who might consider selling a kidney are denied that opportunity in order to protect those among them who would not sell voluntarily from significant harm (Malmqvist 2014).

\section{References}

Awaya, T., L. Siruno, S. J. Toledano, F. Aguilar, Y. Shimazono, and L. D. de Castro. 2009. Failure of informed consent in compensated non-related kidney donation in the Philippines. Asian Bioethics Review 1(2): 138-143.

Goyal, M., R. L. Mehta, L. J. Schneiderman, and A. R. Sehgal. 2002. Economic and health consequences of selling a kidney in India. Journal of the American Medical Association 288(13): 1589-1593.

Koplin, J. 2014. Assessing the likely harms to kidney vendors in regulated organ markets. American Journal of Bioethics (this issue).

Malmqvist, E. 2013. Kidney sales and the analogy with dangerous employment. Health Care Analysis (published online 27 December 2013, DOI: 10.1007/s10728-013-0270-3).

Malmqvist, E. 2014. Are bans on kidney sales unjustifiably paternalistic? Bioethics 28(3): $110-118$. 
Naqvi, S. A. A., B. Ali, F. Mahzar, M. N. Zafar, and S. A. H. Rizvi. 2007. A socioeconomic survey of kidney vendors in Pakistan. Transplant International 20(11): 934-939.

Omar, F., G. Tufveson, and S. Welin. 2010. Compensated living kidney donation: A plea for pragmatism. Health Care Analysis 18(1): 85-101.

Wilkinson, S. 2003. Bodies for Sale: Ethics and Exploitation in the Human Body Trade.

London: Routledge.

Zargooshi, J. 2001. Quality of life of Iranian kidney “donors”. Journal of Urology 166(5): 1790-1799. 